\title{
Debate. How should steps per day be reported-a proposal using data from Africa
}

\author{
lan Cook
}

\begin{abstract}
Recent reviews published in the IJBNPA provide more definitive ranges of ambulatory activity usually found in four general age groups, and how step data relates to public health guidelines. Of note in these reviews was the lack of data from Developing Countries. Apart from the lack of published data, available data was not presented in a format conducive to inclusion in the reviews. Consequently, this paper presents available pedometry data from Africa, such that it is easily available for inclusion in future comparisons. Also addressed is the need to consider adjusting prevalence data according to standard population age structures.
\end{abstract}

Keywords: Pedometer, Physical activity, Africa

\section{Correspondence Introduction}

Recently, three reviews were published in the IJBNPA which address the need to update accumulating evidence, relating to step-based recommendations, with evidence-based physical activity guidelines [1-3]. What is apparent in the reviews is the lack of pedometry data from Developing Countries, specifically Africa. The primary reason for the absence of African data in the reviews is simply the dearth of reported African data. However, the published data that is available $[4,5]$ could not be included [2] because of the reporting format in the original papers. The unadjusted step data was reported either as mean(sd) by age quartile [4] or mean (sd) by step quartile [5] and adolescent/adult and adult/ elderly age categories overlapped substantially in the first and last quartiles, respectively. With regards to the reviews [1-3] a possible area of concern is that the reported prevalence statistics, especially for adults, do not appear to have been adjusted to standard populations, making comparison across moderate to large scale surveillance studies difficult. Consequently, the purpose of this paper is to present the available step data from African samples such that the data can be used in future reviews and to encourage researchers especially from

\footnotetext{
Correspondence: ian.cook@ul.ac.za

Physical Activity Epidemiology Laboratory, University of Limpopo (Turfloop Campus), P.O. Box 459, Fauna Park, Polokwane 0787, Limpopo Province,
} South Africa
Developing Countries to report step data in a more standardised format.

\section{Methods}

The methodology for the two cross sectional studies conducted in a rural African population [6-8] is described in detail elsewhere $[4,5]$. The age range is 1496 years and the average daily step range is 1048-35534 steps $[4,5]$. The first smaller study $(\mathrm{n}=121)$ conducted in 2003-2004 on females only, used the Yamax Digiwalker SW-401 pedometer [4]. The second larger study ( $n=789$ ) collected data from both sexes in 2005-2007 using the New Lifestyles NL-2000 pedometer [5].

The suggested reporting format contains 8 step levels $(<2500,2500-4999,5000-7499,7500-9999,10000-$ 12499, 12500-14999, 15000-17499, >17500) [9]. Unlike samples from Developed Countries which tend to require more sedentary categories, samples from Developing Countries often report very high step values [5] due to the dependence on subsistence activities which include substantial amounts of walking [10]. Therefore, an upper limit of 17500 steps was chosen [11]. The recent reviews used age ranges for children, adolescents, adults and the elderly of 6-11.9, 12-19.9, 20-65 and > 65 years, respectively [1-3]. However, in the current data sets, because the sampling includes adolescents from 14 to 19.9 years and the age distribution within the adult and elderly age categories are skewed, sub-categories were created. 
The reporting format is included as supplementary material in two spreadsheet files. The first file [see Additional file 1] consists of three tables containing descriptive data and step data across age, sex and step index for both data sets. The descriptive statistics include mean(sd), percentages and $n$. The second file [see Additional file 2] uses a simple methodology [12] to adjust prevalence statistics to specified populations using fourand eight category step indices across standard demographic age ranges. Where necessary, data were analysed using appropriate statistical software (SPSS Inc. PASW: Release 18.0.3 SPSS Corp, Chicago, Il, 2010). Significance was set at $p<0.05$.

\section{Results and discussion}

Because the data $[4,5]$ was collected in one field site [6-8], the data sets were checked for duplicates. Twenty seven duplicates were identified, all female with 24, 2 and 1 in the adult, adolescent and elderly categories, respectively. The duplicate group tended to be slightly older and heavier and walked less (Age: delta $=+0.9$ years, $p=0.018$; BMI: delta $=+4.2 \mathrm{~kg} . \mathrm{m}^{-2}, p=0.048$; Ambulation: delta $=-848$ steps, $p=0.437$ ). Excluding duplicate data [5] changed average step data by $<85$ steps and the crude step index prevalence changed by $\leq 0.7 \%$. Consequently, duplicate data was included in the analysis.

Step values for adolescents fell within the ranges observed for children from Developed Countries [1] with no or little decline over the 14-19.9 year age range. Adults demonstrated a steady decline over the 20-65 year age range although the mean values at all age ranges were well above the minimum recommendation of 7000-8000 steps/day [2]. The adult age range spans 45 years and should reflect the populations' age distribution for that category. For instance, the adult crude and adjusted prevalence for $\geq 10000$ steps for one of the data sets [5] are $65.8 \%$ and $68.8 \%$, respectively using the INDEPTH age structure [13] as the standard. In the elderly, $>65$ years, $>20 \%$ achieve $\geq 10000$ steps/day, and mean step values were in the upper end of those observed for Developed Countries [3]. The generally elevated step values for all age groups reflect the greater reliance on subsistence living and active transport and are a useful comparison for future studies.

\section{Conclusions}

Researchers in Developing Countries, especially Africa, are strongly encouraged to collect and publish step count data. Without such data there is the possibility of bias toward values obtained in Developed Countries. Importantly, systematic reviews can only include published data that is appropriately formatted.

\section{Additional material}

Additional file 1: Sheet 1-Table 1. Age and body mass index of free-living rural black South Africans by step index. Sheet 2-Table 2. Free-living ambulatory profile of rural black South African women ( $n=$ 121, $19-56$ years) by age and step index (2003-2004). Sheet 3-Table 3. Free-living ambulatory profile of rural black South Africans ( $n=789$, 1496 years) by gender, age and step index (2005-2007).

Additional file 2: Sheet 1-Age adjustment for 4-category step index prevalence. Sheet 2-Age adjustment for 8-category step index prevalence. Sheet 3-Age profile chart. Sheet 4-Instructions, references.

\section{Acknowledgements}

The Research Development and Administration Division of the University of Limpopo (Turfloop Campus) and the Thuthuka and Institutional Research Development Programmes of the National Research Foundation of South Africa supported the studies $[4,5]$.

\section{Competing interests}

The author declares that they have no competing interests.

Received: 5 September 2011 Accepted: 6 February 2012 Published: 6 February 2012

\section{References}

1. Tudor-Locke C, Craig C, Beets M, Belton S, Cardon G, Duncan S, Hatano Y, Lubans D, Olds T, Raustorp A, Rowe D, Spence J, Tanaka S, Blair S: How many steps/day are enough? For children and adolescents. Int J Behav Nutr Phys Act 2011, 8:78.

2. Tudor-Locke C, Craig C, Brown W, Clemes S, De Cocker K, Giles-Corti B, Hatano Y, Inoue S, Matsudo S, Mutrie N, Oppert JM, Rowe D, Schmidt M, Schofield G, Spence J, Teixeira P, Tully M, Blair S: How many steps/day are enough? For adults. Int J Behav Nutr Phys Act 2011, 8:79.

3. Tudor-Locke C, Craig C, Aoyagi Y, Bell R, Croteau K, De Bourdeaudhuij I, Ewald B, Gardner A, Hatano Y, Lutes L, Matsudo S, Ramirez-Marrero F, Rogers L, Rowe D, Schmidt M, Tully M, Blair S: How many steps/day are enough? For older adults and special populations. Int J Behav Nutr Phys Act 2011, 8:80.

4. Cook I, Alberts M, Lambert EV: Relationship between adiposity and pedometer-assessed ambulatory activity in adult, rural African women. Int J Obes 2008, 32:1327-1330.

5. Cook I, Alberts M, Brits JS, Choma S, Mkhonto SS: Descriptive epidemiology of ambulatory activity in rural, black South Africans. Med Sci Sports Exerc 2010, 42:1261-1268.

6. Alberts M, Burger S: INDEPTH DSS Site Profiles: Dikgale DSS, South Africa. In Population and Health in Developing Countries. Volume 1. Population, Health, and Survival at INDEPTH Sites. Edited by: Sankoh OA, Kahn K, Mwageni E, Ngom P, Nyarko P. Ottawa: IDRC; 2002:207-211.

7. Alberts M, Urdal P, Steyn K, Stensvold I, Tverdal A, Nel JH, Steyn NP: Prevalence of cardiovascular diseases and associated risk factors in a rural black population of South Africa. Eur J Cardiovasc Prev Rehabil 2005, 12:347-354.

8. Cook I, Alberts M, Burger S, Byass P: All-cause mortality trends in Dikgale, rural South Africa, 1996-2003. Scand J Public Health 2008, 36:753-760.

9. Tudor-Locke C, Hatano Y, Pangrazi RP, Kang M: Revisiting "how many steps are enough?". Med Sci Sports Exerc 2008, 40:S537-S543.

10. Cook l, Alberts M, Lambert EV: Development of a four-item physical activity index from information about subsistence living in rural African women: a descriptive, cross-sectional investigation. Int J Behav Nutr Phys Act 2009, 6:75.

11. Bassett DR, Schneider PL, Huntington GE: Physical activity in an Old Order Amish community. Med Sci Sports Exerc 2004, 36:79-85.

12. Joubert G: Appendix 1: Standardisation (adjustment) of rates. In Epidemiology: a research manual for South Africa. Edited by: Joubert G, Ehrlich R, Katzenellenbogen J, Karim SA. Cape Town: Oxford University Press; 2009:339-342. 
13. Clark S, Ngom P: Comparing mortality patterns at INDEPTH sites. In Population and Health in Developing Countries. Volume 1. Population, Health, and Survival at INDEPTH Sites. Edited by: Sankoh OA, Kahn K, Mwageni E, Ngom P, Nyarko P. Ottawa: IDRC; 2002:51-82.

doi:10.1186/1479-5868-9-7

Cite this article as: Cook: Debate. How should steps per day be reported-a proposal using data from Africa. International Journal of Behavioral Nutrition and Physical Activity 2012 9:7.

Submit your next manuscript to BioMed Central and take full advantage of:

- Convenient online submission

- Thorough peer review

- No space constraints or color figure charges

- Immediate publication on acceptance

- Inclusion in PubMed, CAS, Scopus and Google Scholar

- Research which is freely available for redistribution

Submit your manuscript at www.biomedcentral.com/submit
() Biomed Central 